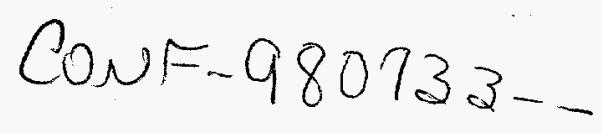

\title{
CALIBRATION MEASUREMENTS USING THE ORNL FISSILE MASS FLOW MONITOR
}

\author{
José March-Leuba, Taner Uckan, James Sumner, John Mattingly, John Mihalczo \\ Oak Ridge National Laboratory, ${ }^{\text {P. }}$. O. Box 2008, Oak Ridge, TN 37831-6010

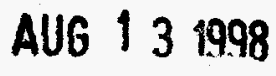 \\ INTRODUCTION

This paper presents a demonstration of fissile-mass-flow measurements using the Oak Ridge National Laboratory (ORNL) Fissile Mass Flow Monitor in the Paducah Gaseous Diffusion Plant (PGDP). This Flow Monitor is part of a Blend Down Monitoring System (BDMS) that will be installed in at least two Russian Federation (R.F.) blending facilities.

The key objectives of the demonstration of the ORNL Flow Monitor are two: (a) demonstrate that the ORNL Flow Monitor equipment is capable of reliably monitoring the mass flow rate of ${ }^{235} \mathrm{UF}_{6}$ gas, and (b) provide a demonstration of ORNL Flow Monitor system in operation with UF $_{6}$ flow for a visiting R.F. delegation. These two objectives have been met by the PGDP demonstration, as presented in this paper.

\section{BACKGROUND}

Recent HEU Transparency agreements between the United States (US) and the R. F. provide for the monitoring of the blending of highly enriched uranium (HEU) at an assay of $\sim 90 \%$ with low enrichment uranium (LEU) at an assay of $\sim 1.5 \%$ to produce reactor-grade material at an assay of $\sim 4 \%$ to be used in U.S. nuclear power plants. The Flow Monitor component of the BDMS has been developed by ORNL to provide unattended monitoring of the HEU blending operations at the R.F. facilities. The ORNL Flow Monitor measures the mass flow rate of gaseous uranium hexafluoride $\left(\mathrm{UF}_{6}\right)$ flowing through a process pipe, without requiring direct contact with the gas in the pipe. As a prelude to the installation of U.S.-provided monitoring equipment in R.F. blending facilities, it was decided to demonstrate the operation of the Flow Monitor in a U.S. nuclear facility with $U_{6}$ gas. This demonstration would also provide the opportunity for a R.F. delegation to observe the operation of the Flow Monitor equipment before the installation activities in their facilities.

\section{DESIGN OF THE DEMONSTRATION STAND}

To properly simulate operation of the Flow Monitor system in a R.F. HEU blending facility, gaseous $\mathrm{UF}_{6}$ at an assay of $\sim 1.5 \%$ was required. Rather than arranging a dedicated facility to test the Flow Monitor equipment, it was decided to perform the demonstration at an existing facility where $U_{6}$ was readily available for performing the test. The demonstration was performed at The Paducah Gaseous Diffusion Plant (PGDP), which is operated by Lockheed Martin Utility Services, Inc. (LMUS) for the US Enrichment Corporation (USEC).

A special-purpose demonstration loop was designed and installed in the PGDP cascade to accommodate the equipment. The supply side of the loop was connected to the compressor discharge in the product withdrawal facility. The outlet side of the loop was connected to the

\footnotetext{
${ }^{1}$ Managed by Lockheed Martin Energy Research Corp. For the U.S. Department of Energy under contract DE-AC05-960R22464
}

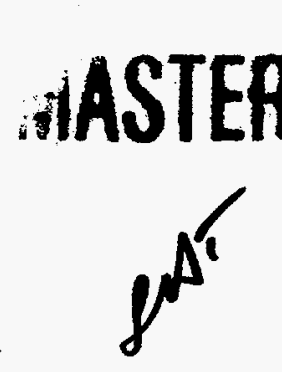




\section{DISCLAIMER}

This report was prepared as an account of work sponsored by an agency of the United States Government. Neither the United States Government nor any agency thereof, nor any of their employees, make any warranty, express or implied, or assumes any legal bability or responsibility for the accuracy, completeness, or usefulness of any information, apparatus, product, or process disclosed, or represents that its use would not infringe privately owned rights. Reference herein to any specific commercial product, process, or service by trade name, trademark, manufacturer, or otherwise does not necessarily constitute or imply its endorsement, recommendation, or favoring by the United States Government or any agency thereof. The views and opinions of authors expressed herein do not necessarily state or reflect those of the United States Government or any agency thereof. 


\section{DISCLAIMER}

Portions of this document may be illegible in electronic image products. Images are produced from the best available original document. 
suction side of a compressor, providing the needed $\mathrm{UF}_{6}$ pressure differential across the demonstration loop. Manual control valves were included in the added process piping of the loop to permit demonstrating the $\mathrm{FM}$ at varying flow rates and $\mathrm{UF}_{6}$ pressures.

\section{MEASUREMENT RESULTS}

The primary emphasis on the PGDP demonstration was to demonstrate the operation of the Flow Monitor equipment at operating conditions similar to those in the LEU lines at the R.F. HEU blending facilities. While it was not possible to demonstrate the Flow Monitor equipment operation at all of the assay levels, corresponding operating conditions were developed to simulate the operation of the Flow Monitor at these conditions by varying the $\mathrm{UF}_{6}$ gas pressure. This resulted in an "effective" ${ }^{235} \mathrm{U}$ density that simulated different assay levels. Table 1 shows a comparison of relevant parameters in a typical R.F. blending facility compared to the conditions measured during the PGDP demonstration. As seen in the table, the gas velocity and mass flow conditions measured in PGDP cover all of the expected operation range in a typical R.F. HEU blending facility. The measured ${ }^{235} \mathrm{U}$ densities cover the expected range of operation in both the blend stock and product LEU lines, which represent more difficult measurements than the HEU line. Due to facility constraints, the lowest pressure achieved during the PGDP demonstration was $1.5 \mathrm{psia}$, which is higher than the expected $0.8 \mathrm{psia}$, but pressure effects are well understood and do not compromise the results of this demonstration.

In addition to demonstrating equipment operation at conditions representative of the R.F. HEU blending facilities, the equipment was operated under a variety of pressures and flows to fully characterize its operational abilities at possible off-normal conditions. As shown in Figure 1, the ORNL Flow Monitor equipment was operated successfully within an operating envelope bounded by pressures ranging from 1.5 to 4.5 psia and gas velocities ranging from $0.03 \mathrm{~m} / \mathrm{s}$ to $2.2 \mathrm{~m} / \mathrm{s}$. These conditions include both, laminar and turbulent flow regimes, and the operation of the ORNL Flow Monitor has been successfully demonstrated under both regimes.

Figure 2 shows a typical result from the PGDP demonstration measurements for a condition with a gas velocity of $\sim 0.5 \mathrm{~m} / \mathrm{s}$ and a source-detector separation of $\sim 3 \mathrm{~m}$. As seen in this figure, the neutron-absorber shutter opens at time zero, resulting in an instantaneous response at the detector location. This response is caused by a change in gamma-ray background induced by the change of neutron flux in the moderator. A fission fragment pulse is clearly observable with a time delay of $\sim 6 \mathrm{~s}$ (equal to $3 \mathrm{~m}$ separation divided by $0.5 \mathrm{~m} / \mathrm{s}$ velocity). The ORNL Flow Monitor averages a large number of shutter motions to reduce the uncertainty on the measurement and, then, processes the data to identify a time delay and a pulse amplitude. The gas velocity is inferred from the time delay, and the ${ }^{235} \mathrm{U}$ concentration is related to the pulse amplitude. The fissile mass-flow rate is calculated by multiplying the gas velocity times the fissile concentration:

Figure 3 shows the fission fragment pulses identified by the ORNL Flow Monitor algorithm using two different sets of detectors, located at different distances from the source. As expected, the fission fragments arrive three times faster to the detector located $\sim 1 \mathrm{~m}$ from the source than to the detector at $\sim 3 \mathrm{~m}$ distance. The pulse amplitude for the $\sim 3 \mathrm{~m}$ detector is significantly lower than the amplitude of the $\sim 1 \mathrm{~m}$ detector; nevertheless, the Flow Monitor algorithm identifies automatically the same velocity, density, and mass flow for both detectors.

The ORNL Flow Monitor has also performed successfully under transient conditions. Figure 4 shows the response to a slow ramp down in assay level. As seen in this figure, the ${ }^{235} \mathrm{UF}_{6}$ mass flow decreased as the $\mathrm{UF}_{6}$ enrichment was reduced, while the total $\mathrm{UF}_{6}$ mass flow remained constant. The measured ${ }^{235} \mathrm{UF}_{6}$ mass flow reduction is $\sim 30 \%$, which is consistent with an assay change from $\sim 1.5 \%$ to $\sim 1.1 \%$. 
The ORNL Flow Monitor was also evaluated for its ability to accurately detect a temporary loss in flow and repeatability during the subsequent flow restart. Figure 5 shows the resulting output from the Flow Monitor during one of these demonstrations. As can be seen from the figure, the Flow Monitor proved capable of properly monitoring transients in the flow of $U_{6}$ through the demonstration stand.

A key characteristic of the ORNL Flow Monitor is the ability to trace fission fragments induced in the HEU line through the blending point and to detect them in the product LEU line. This feature adds significant Transparency verification to the blending process because it allows for the tracing of HEU gas to the product line. This feature has been successfully demonstrated at PGDP, and a typical result is shown in Figure 6.

\section{CONCLUSIONS}

The following lists the more significant accomplishments of the PGDP demonstration of the BDMS Flow Monitor:

1. Operation of the ORNL Flow Monitor has been successfully demonstrated with $\mathrm{UF}_{6}$ gas flow under realistic conditions representative of LEU flows in typical R.F. blending facilities.

2. The ORNL Flow Monitor has proven to be able to monitor the mass flow rate of $\mathrm{UF}_{6}$ with accuracy better than $\pm 25 \%$, as required to implement Transparency agreements.

3. Traceability of HEU gas to the product LEU line has been successfully demonstrated.

4. Operation of the ORNL Flow Monitor has been successfully demonstrated under transient conditions, including an assay change from $\sim 1.5 \%$ to $\sim 1.1 \%$.

5. The ORNL Flow Monitor equipment has proven to be reliable during unattended operation.

In summary, the PGDP demonstration documented in this paper has shown that the ORNL Flow Monitor equipment is capable of reliably monitoring the mass flow rate of $\mathrm{UF}_{6}$ gas, as required to implement the U.S. R.F. HEU Transparency agreements.

Table 1. Comparison of operating conditions in a typical R.F. blending facility versus conditions measured in the PGDP demonstration.

\begin{tabular}{|c|c|c|c|c|}
\hline & \multicolumn{3}{|c|}{ TYPICAL R.F. BLENDING FACILITY } & \multirow{2}{*}{$\begin{array}{c}\text { PGDP } \\
\text { DEMO } \\
\text { STAND }\end{array}$} \\
\hline & HEU & $\begin{array}{c}\text { BLEND } \\
\text { STOCK } \\
\text { LEU }\end{array}$ & $\begin{array}{l}\text { PRODUCT } \\
\text { LEU }\end{array}$ & \\
\hline Velocity $(\mathrm{m} / \mathrm{s})$ & $\sim 0.05$ & -1.5 & $\sim 1.5$ & $0.03-2.2$ \\
\hline${ }^{235} \mathrm{UF}_{6}$ Mass Flow (g/s) & $\sim 0.25$ & $\sim 0.15$ & $\sim 0.45$ & $0.1-0.7$ \\
\hline${ }^{235} \mathrm{UF}_{6}$ Density $(\mathrm{g} / \mathrm{m})$ & $\sim 5$ & $\sim 0.1$ & $\sim 0.3$ & $0.1-0.45$ \\
\hline Enrichment & $-90 \%$ & $-1.5 \%$ & $\sim 4.5 \%$ & $1.1 \%-1.55 \%$ \\
\hline Pressure (psia) & $\sim 0.8$ & $\sim 0.8$ & $\sim 0.8$ & $1.5-4.5$ \\
\hline
\end{tabular}




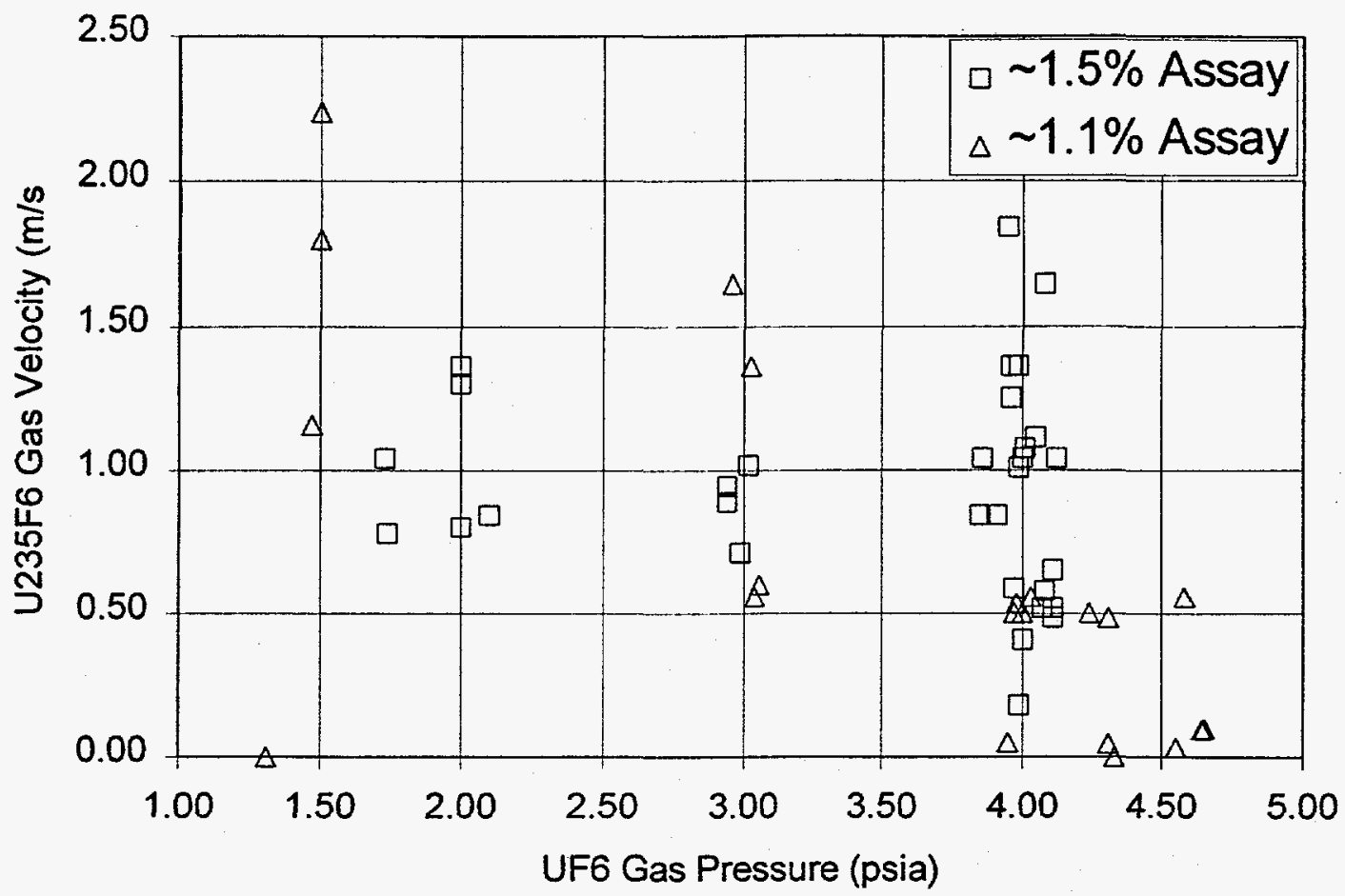

Figure 1. Operating conditions measured during the PGDP demonstration cover the expected range of operation in blend-stock and product LEU lines of a typical blending facility

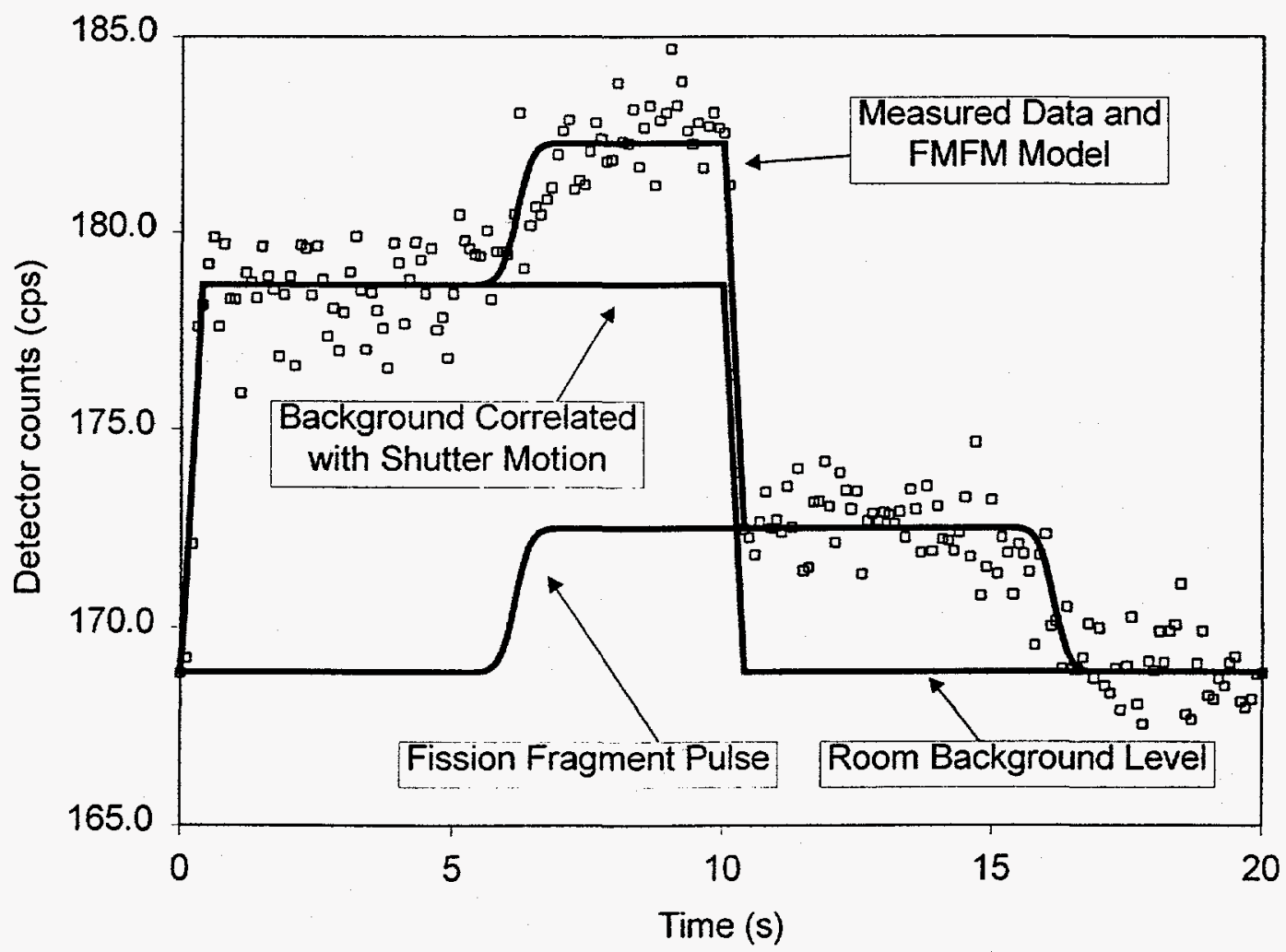

Figure 2. Typical results of a Flow Monitor measurement, showing the correlated background and fission fragment pulse components of the measured signal. 


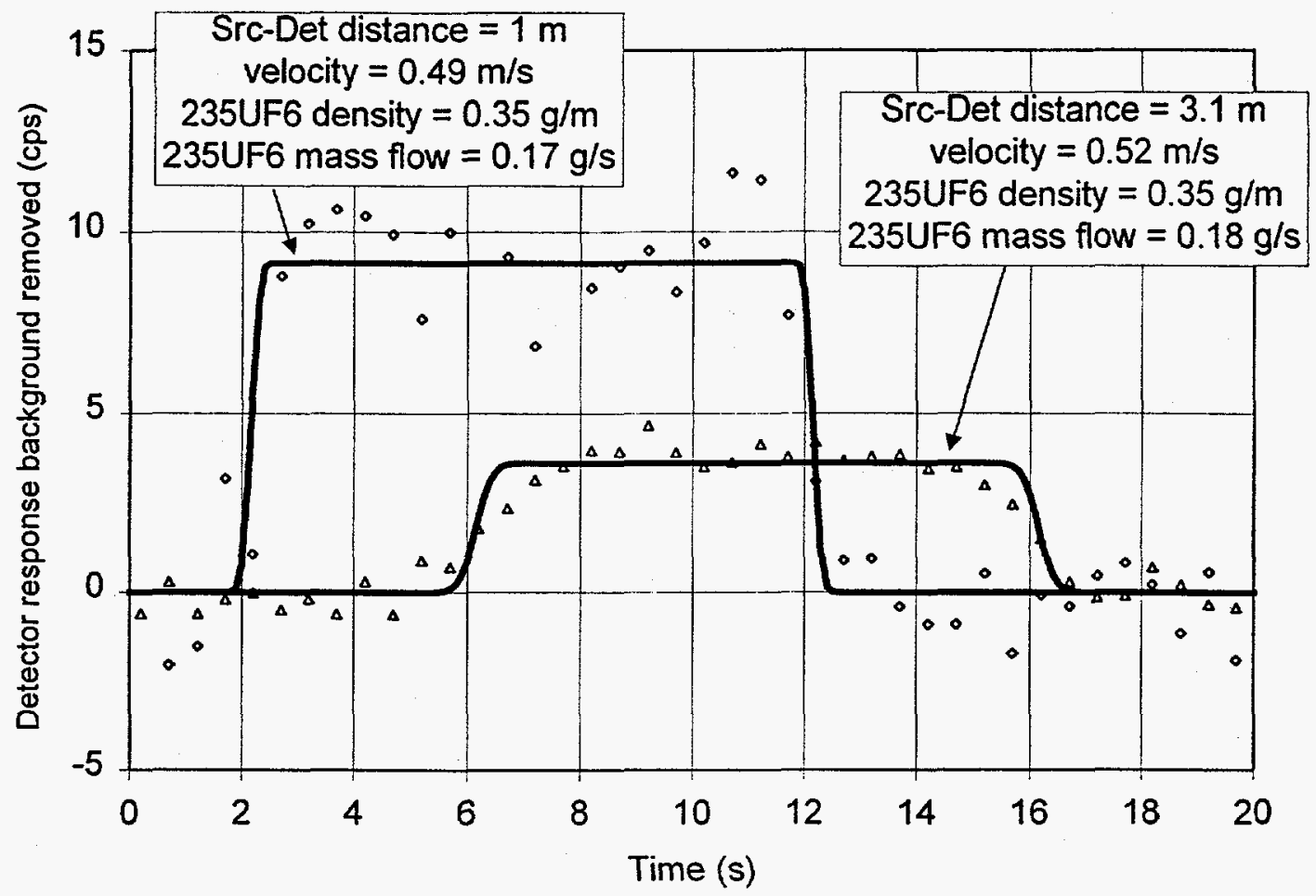

Figure 3. For the same flow conditions, the Flow Monitor measures the same velocity and mass flow at two different source-detector distances.

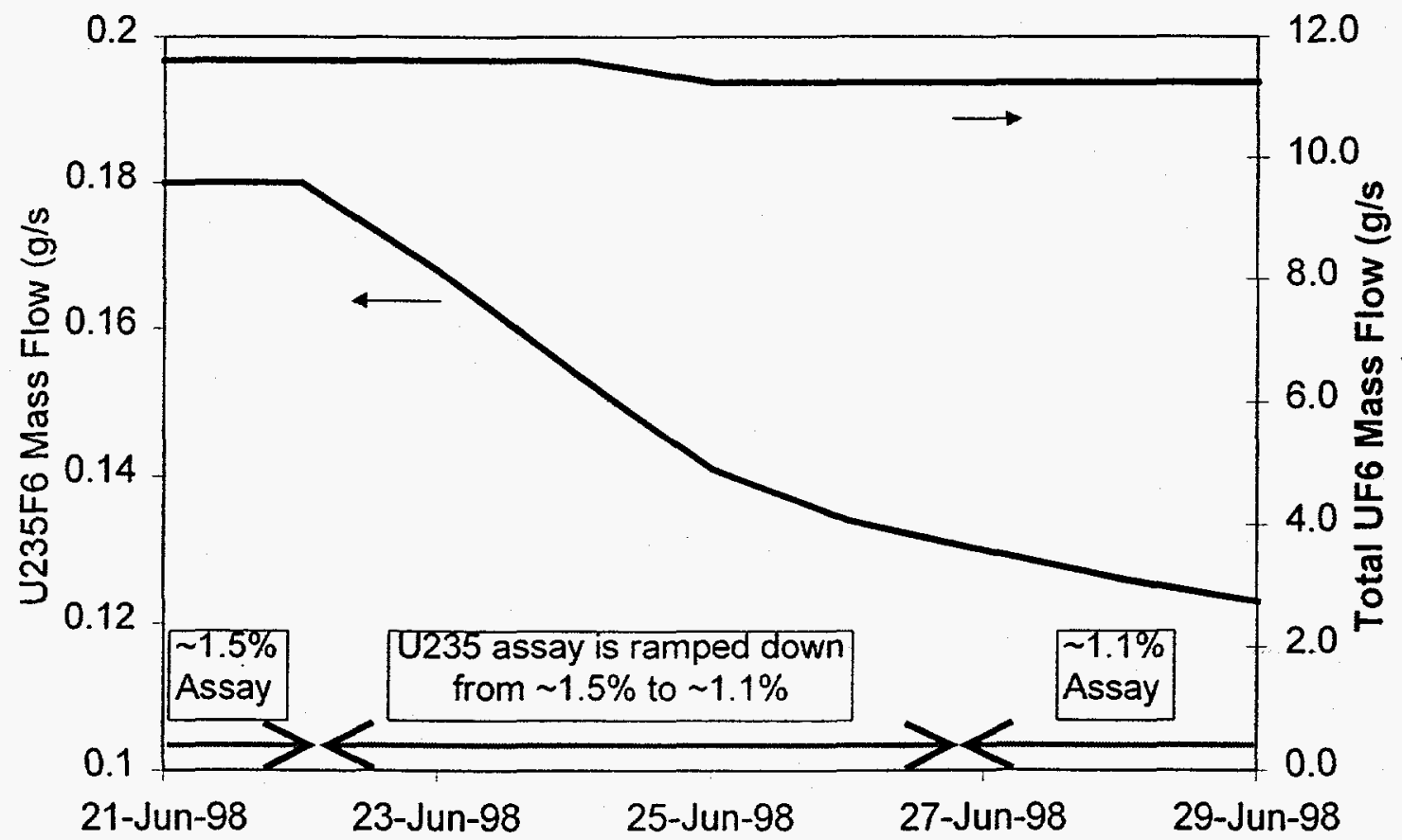

Figure 4. Flow Meter responds successfully to a reduction in ${ }^{235} \mathrm{U}$ mass flow induced by a slow ramp down in assay level while maintaining total $U$ mass flow and pressure (4 psia) constant. 


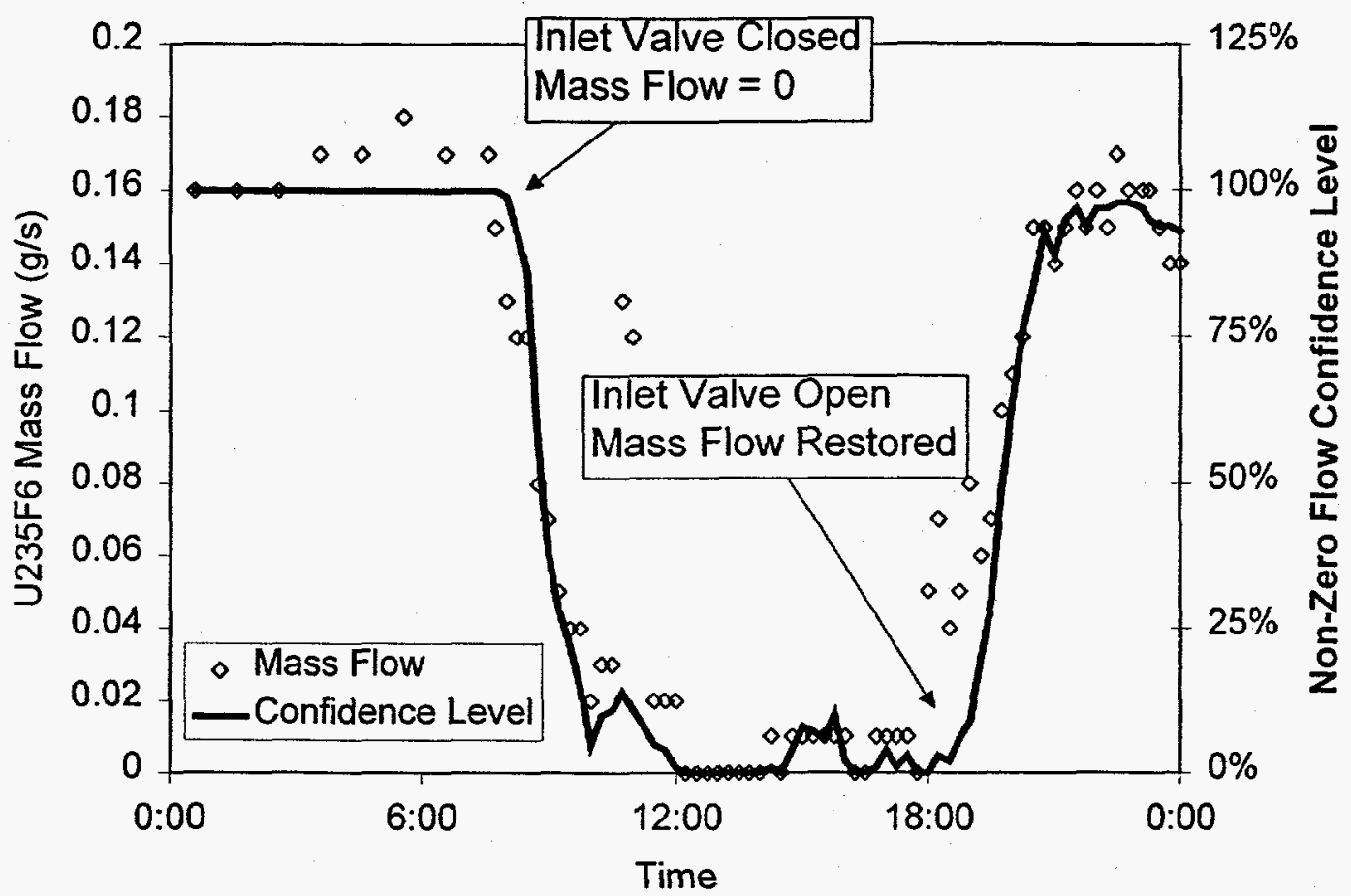

Figure 5. ORNL Flow Meter responded successfully to a mass flow. Flow and confidence level drop to -zero when a control valve is closed; both recover to the original value when the valve is reopen.

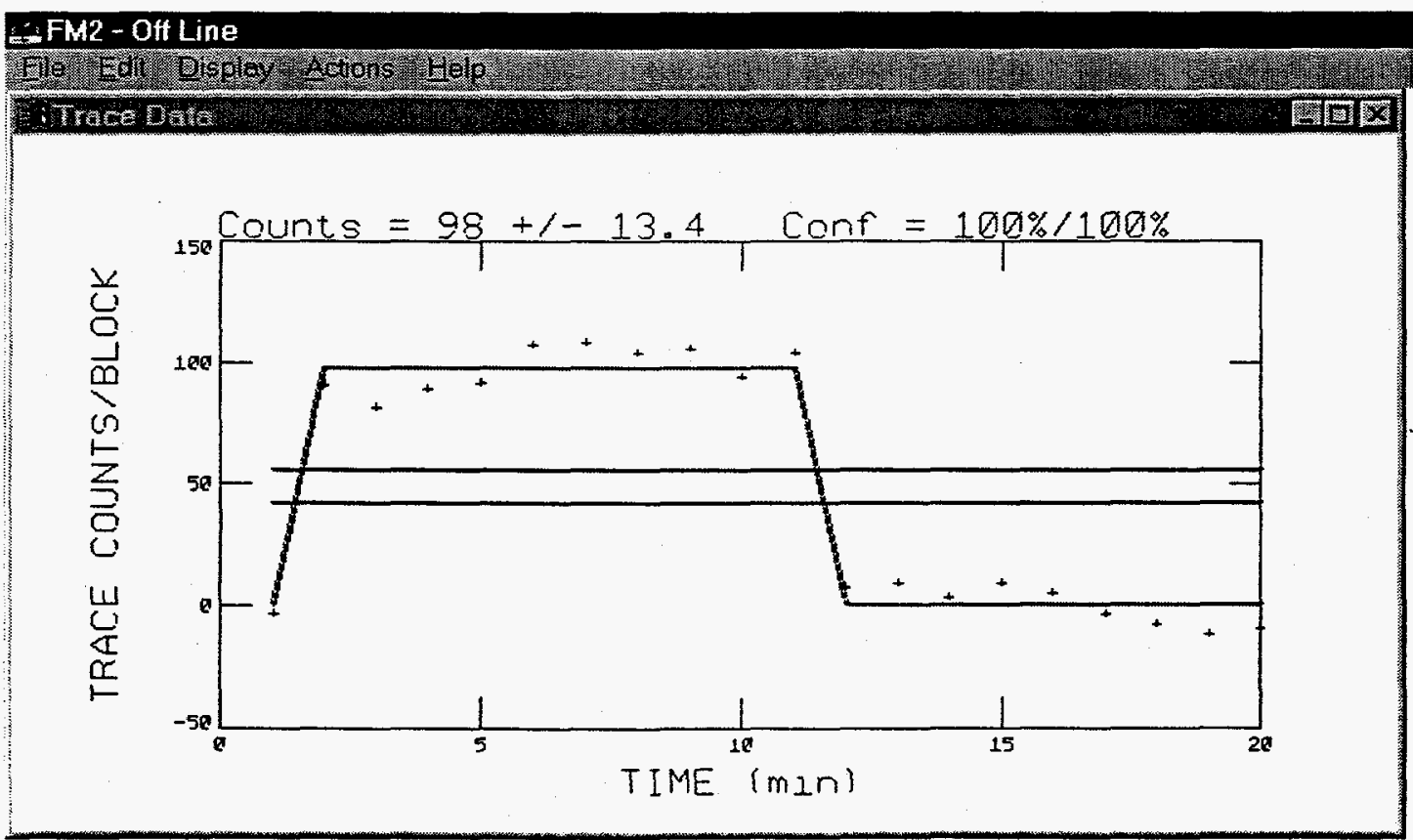

Figure 6. Traceability of HEU gas to the Product LEU line has been demonstrated at PGDP. 